
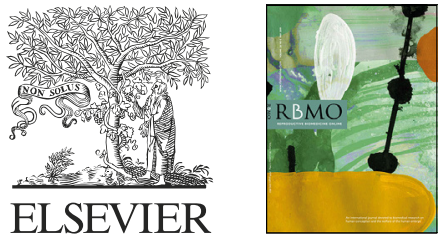

ARTICLE

\title{
Potential benefits of the use of sympathomimetics for asthmatic disease, on semen quality in men of subfertile couples
}

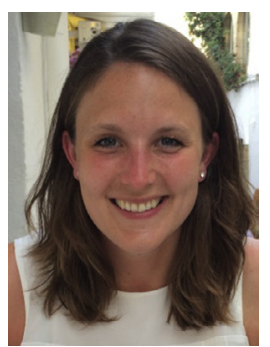

\begin{abstract}
BIOGRAPHY
Eline Oostingh is a MD and $\mathrm{PhD}$ candidate of the Periconception Epidemiology Group as part of the department of Obstetrics and Gynecology at the Erasmus University Medical Center in Rotterdam, the Netherlands. She focuses on maternal and paternal periconception research and health intervention.
\end{abstract}

Elsje C. Oostingh ${ }^{1}$, Nicole A. Huijgen ${ }^{1}$, Rivka Koedooder ${ }^{1}$,

Gert R. Dohle ${ }^{2}$, Bruno HC Stricker ${ }^{3}$, Régine PM Steegers-Theunissen ${ }^{1, *}$

\section{KEY MESSAGE}

In this study, the use of sympathomimetics was positively associated with sperm motility in men of subfertile couples. Further investigation is necessary to test whether men of subfertile couples could benefit from this potential second use of sympathomimetics.

\section{ABSTRACT}

Research question: Is there an association between the use of sympathomimetics for asthmatic disease and semen quality in humans?

Design: Between 2007 and 2012 a prospective cohort study was conducted among couples visiting the preconception counselling clinic at a tertiary hospital in the Netherlands. The study included 882 men of subfertile couples and information on medication use was obtained from self-administered questionnaires. Moreover, data on semen parameters were retrieved from medical records.

Results: The study population of men revealed a mean ( \pm SD) age of $34 \pm 4$ years with a mean body mass index (BMI) of $26.1 \pm 2.3 \mathrm{~kg} / \mathrm{m}^{2}$, and sympathomimetic use was reported by $3.6 \%$. The use of sympathomimetics was positively associated with a $10 \%$ higher sperm motility (beta $10.265 ; 95 \%$ confidence interval [Cl] 3.258-17.272) after adjustment for smoking, alcohol use, age, geographic background, BMI, folic acid supplement use, the four astronomical seasons and asthma/bronchitis. Subgroup analysis between men with total motile sperm count (TMSC) $<$ or $\geq 10$ million showed that this association remained $(P \leq 0.001)$ after adjustment for these confounders. After adjustment for confounders the sperm concentration was also positively associated with the use of sympathomimetics, but only in men with TMSC $\geq 10$ million (beta $0.300 ; 95 \% \mathrm{Cl} 0.032-0.568$ ).

Conclusions: These preliminary data show the potential benefits of the use of sympathomimetics to improve sperm motility in men of subfertile couples, which needs further investigation.

${ }^{1}$ Department of Obstetrics and Gynecology, Erasmus University Medical Center (Erasmus MC), Rotterdam, the Netherlands

2 Department of Urology, Erasmus University Medical Center (Erasmus MC), Rotterdam, the Netherlands

${ }^{3}$ Department of Epidemiology, Erasmus University Medical Center (Erasmus MC), Rotterdam, the Netherlands

C 2020 Reproductive Healthcare Ltd. Published by Elsevier Ltd. All rights reserved.

${ }^{*}$ Corresponding author. E-mail address: r.steegers@erasmusmc.nl (R. P. Steegers-Theunissen). https://doi.org/10.1016/j.

rbmo.2019.12.009 1472-6483/@ 2020 Reproductive Healthcare Ltd. Published by Elsevier Ltd. All rights reserved.

Declaration: The authors report no financial or commercial conflicts of interest.

\section{KEYWORDS}

Drug utilization

Respiratory medicine

Semen parameters

Sympathetic nervous system 


\section{INTRODUCTION}

W orldwide one out of six couples experiences subfertility, which is defined as the failure to conceive after 1 year of regular unprotected intercourse with the same partner (European Society of Human Reproduction and Embryology, 2016; World Health Organization, 2010). Of al subfertile couples, $20-30 \%$ is explained by male subfertility only and in 25-40\% both male and female subfertility are found (European Society of Human Reproduction and Embryology, 2016). Unfortunately, only a few medical treatments are available for male subfertility.

Research from the past two decades has shown that semen quality is influenced by several conditions and modifiable factors, such as obesity, nutrition, smoking and medication use (CBS StatLine Netherlands, 2015; Hayashi et al., 2008; Huijgen et al., 2016, 2017; Samplaski and Nangia, 2015). In the Netherlands, the overall use of medication of the male population of reproductive age (20-60 years) is approaching 55\% (CBS StatLine Netherlands, 2015). Subfertility resulting from medicationinduced endocrine malfunction or injury to germ cells is a largely neglected clinical problem (Hayashi et al., 2008; Huijgen et al., 2016, 2017; Samplaski and Nangia, 2015). The exact potentially toxic effect on the gonads of many commonly used medicines is, however, still largely unknown (Fody and Walker, 1985; Hayashi et al., 2005; Schlegel et al., 1991; Semet et al., 2017; Sjoblom et al., 1998), as is the impact of chronic diseases on male fertility (Eisenberg et al., 2015; Global Initiative for Asthma, 2017; Hayashi et al., 2008).

An example of a very common chronic disease with an overall prevalence in the Netherlands of $6 \%$ is asthma/bronchitis (Boerdam and Knoops, 2016). According to the guidelines of the Dutch College of General Practitioners, these chronic diseases are treated with short-acting inhaled sympathomimetics, a low/ high dose inhaled glucocorticoid or combination of these medicines (The Dutch College of General Practitioners, 2007). In the Netherlands, around $5.6 \%$ of males of reproductive age uses medication for asthma/bronchitis (CBS StatLine Netherlands, 2015). As the adrenergic receptors on which these medications act are also present in the reproductive system, it is postulated that sympathomimetics can also affect spermatogenesis. Therefore, this study aimed to assess associations between the use of sympathomimetics and sperm quality in men of subfertile couples.

\section{MATERIALS AND METHODS}

\section{Study population}

Between 2007 and 2012, couples contemplating pregnancy and visiting the outpatient clinic of the Department of Obstetrics and Gynecology at the Erasmus University Medical Center (Erasmus MC), Rotterdam, the Netherlands, were offered preconception counselling. This special outpatient clinic, 'Achieving a Healthy Pregnancy' (Hammiche et al., 2011), was visited by 2365 men, of whom 2166 provided written informed consent (METC Erasmus MC 04202-77). Men for whom a semen analysis was not performed within 0-70 days prior to the visit or 21 days after the visit were excluded. This window covers the 10 weeks of spermatogenesis during which medication use was assessed and reduces confounding by counselling as this window was independent of exposures and bias due to the exclusion of conditions affecting semen parameters. Men with semen samples provided by microsurgical epididymal sperm aspiration (MESA), percutaneous epididymal sperm aspiration (PESA) or retrograde ejaculation, or with incomplete data or no data on medication use, were also excluded. This resulted in 882 men for further evaluation (FIGURE 1). The study protocol was approved by the Medical Ethical and Institutional Review Board of the Erasmus MC on 25 June 2013.

\section{Data collection}

At study entry, all participants completed a self-administered questionnaire covering (non)-medical conditions at enrolment, which were thoroughly checked by the researcher during the preconception visit, during which anthropometric measurements (height, weight, BMI, waist-hip ratio and blood pressure) were also obtained (Hammiche et al., 2011).

\section{Medication use}

Information on medication use was obtained from self-administered questionnaires and was divided according to the Anatomical Therapeutic Chemical (ATC) classification system (WHO Collaborating Centre for Drug Statistics Methodology, WHO Collaborating Centre for Drug Statistics Methodology, 2017). In this study population short-acting and long-acting beta-2 adrenergic receptor agonists were used for asthma/bronchitis, as well as inhaled corticosteroids (either alone or combined). Information on dosage and duration was not available.

\section{Semen analysis}

Semen samples were collected via masturbation after a required abstinence period of 3-5 days. Within $1 \mathrm{~h}$, samples were liquefied and the semen parameters ejaculate volume, sperm concentration, percentage progressive (type $A+B$ ) and immotile spermatozoa (type $C+D$ ) were assessed according to World Health Organization guidelines (World Health Organization, 2010).

Total sperm count was calculated as the product of ejaculate volume and sperm concentration. Total motile sperm count (TMSC) was calculated as the product of ejaculate volume, sperm concentration and percentage progressive motile spermatozoa (type $A+B$ ). Normospermia was defined as TMSC $\geq 10$ million. All semen analyses were performed by expert laboratory staff at the Erasmus MC. Semen samples were not routinely collected as part of the study, but only on the clinical indication of subfertility. Semen parameters were therefore retrieved from medical records to obtain all the data required for this study.

\section{Statistical analyses}

Primary analyses included descriptive statistics providing characteristics of the study sample, expressed as medians with interquartile ranges or absolute numbers with percentages and were compared using either Mann-Whitney U-tests or chi-squared tests. A normal distribution of the semen parameters was achieved with root transformation of ejaculate volume and sperm count, and fourth root transformation of sperm concentration and TMSC. Univariable and multivariable linear regression models were applied to study associations between the use of sympathomimetics and semen parameters.

After the crude analysis, an adjusted model was constructed including the potential confounders body mass index (BMI), alcohol use, smoking, 


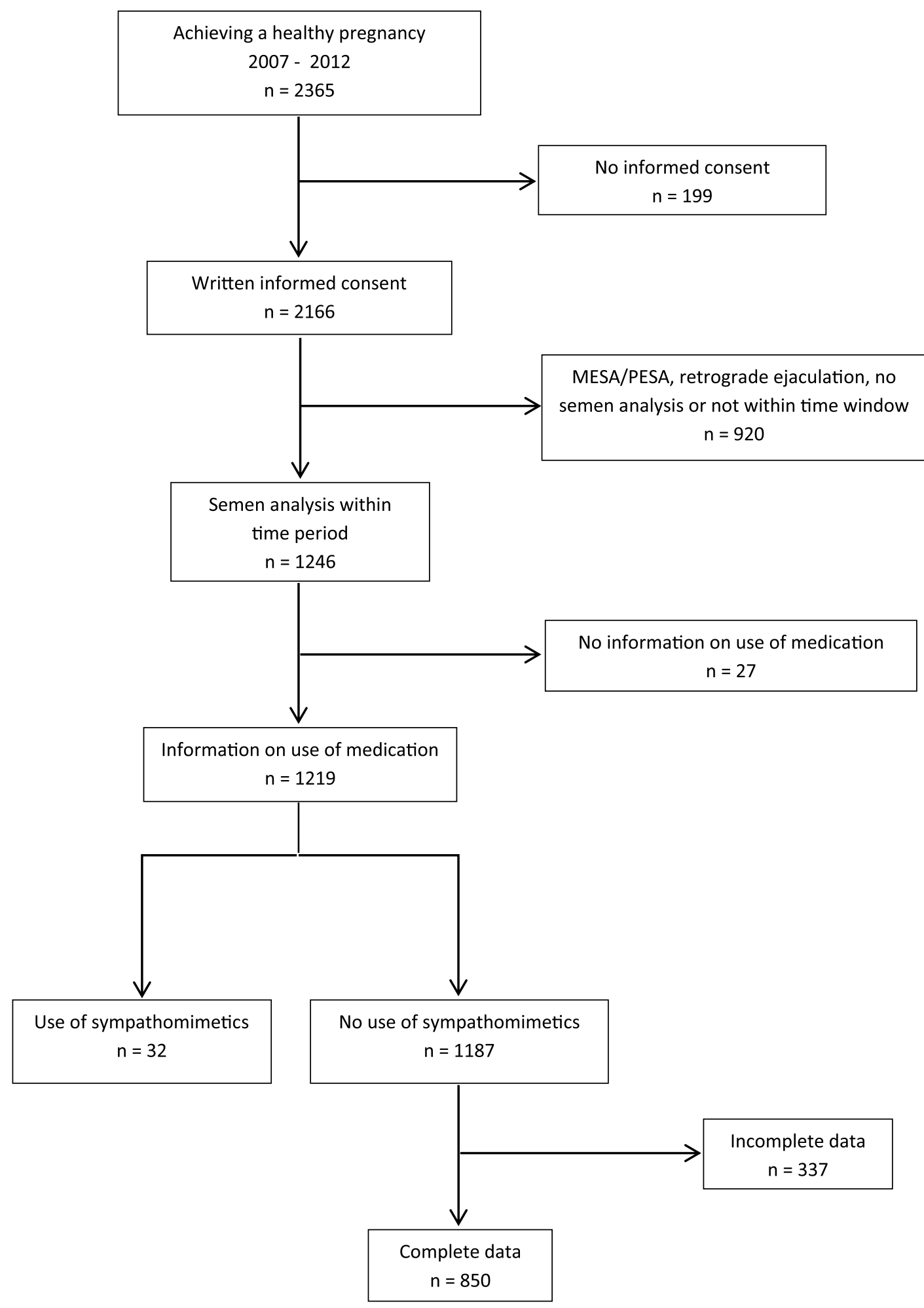

FIGURE 1 Flow diagram of included and excluded men (MESA = microsurgical epididymal sperm aspiration; PESA = percutaneous epididymal sperm aspiration).

geographic background, age and folic acid supplement use, based on their associations with semen parameters. An adjustment was also made for the four astronomical seasons. As a final step, confounding by indication was addressed because this is a bias frequently encountered in observational epidemiologic studies of medication effects. To do this, an additional adjustment was made for the presence or absence of asthmatic disease. Finally, a similar multivariable linear regression analysis was performed, stratified for men with a TMSC $<$ or $\geq 10$ million. Estimates are expressed by regression coefficients (beta) with confidence intervals $(95 \% \mathrm{Cl})$. All analyses were performed using SPSS 
TABLE 1 GENERAL CHARACTERISTICS OF THE STUDY POPULATION OF MEN OF SUBFERTILE COUPLES VISITING THE PRECONCEPTION OUTPATIENT CLINIC 'ACHIEVING A HEALTHY PREGNANCY' $(\mathbf{N}=882)$

\begin{tabular}{|c|c|c|c|}
\hline & Users of sympathomimetics $(n=32)$ & Non-medication users $(n=850)$ & \\
\hline Age (years) & 35 (32-39) & $34(30-39)^{a}$ & \\
\hline $\mathrm{BMI}\left(\mathrm{kg} / \mathrm{m}^{2}\right)$ & $27.4(24.4-30.7)^{b}$ & $26.1(23.9-28.5)^{c}$ & \\
\hline Geographic background (Dutch) & $21(65.6)$ & $538(63.6)^{d}$ & \\
\hline Smoking (Yes) & $7(21.9)$ & $281(33.1)^{e}$ & \\
\hline Alcohol (Yes) & $27(84.4)$ & $602(71.0)^{f}$ & \\
\hline Recreational drugs (Yes) & $1(3.1)$ & $65(7.6)$ & \\
\hline Folic acid supplement use (Yes) & $7(24.1)^{g \star \star}$ & $45(6.0)^{h}$ & \\
\hline Semen parameters: & & & $\begin{array}{l}\text { Lower reference limit } \\
(\mathrm{WHO}, 2010)\end{array}$ \\
\hline Ejaculate volume (ml) & $2.75(1.45-3.60)$ & $2.80(1.80-3.90)$ & 1.5 \\
\hline Sperm concentration $\left(10^{6} / \mathrm{ml}\right)$ & $33(11-81)$ & $26(9-59)$ & 15 \\
\hline Total sperm count (106/ejaculate) & $60.8(17.5-182)$ & $64.8(19.7-146)$ & 39 \\
\hline Total motile sperm count (10\%/ejaculate) & $30.8(7.5-89.4)$ & $24.5(4.1-68.4)$ & 10 \\
\hline Progressive motile spermatozoa $(A+B)(\%)$ & $48(39-53)^{\star}$ & $38(23-49)$ & 32 \\
\hline Duration of sexual abstinence (days) & $4(3-5)^{i}$ & $4(3-7)^{j}$ & \\
\hline
\end{tabular}

Values are expressed as median (IQR) or number (\%); chi-squared and Mann-Whitney tests were performed: ${ }^{\star} P<0.05$; ${ }^{\star \star} P<0.001$

Missing items: two for age, one ${ }^{b}$ and $36^{c}$ for $\mathrm{BMI}$, four ${ }^{\mathrm{d}}$ for geographic background, one ${ }^{\mathrm{e}}$ for smoking, two ${ }^{f}$ for alcohol, and three and $^{\mathrm{a}} 5^{\mathrm{h}}$ for folic acid supplement use, $22^{\mathrm{i}}$ and $340^{j}$ for duration of sexual abstinence.

$\mathrm{BMI}=$ body mass index

Statistics for Windows, Version 21.0 (IBM Corp., Armonk, NY, USA). P-values <0.05 were considered statistically significant.

\section{RESULTS}

General characteristics of the study population $(n=882)$ and excluded population ( $n=1483$ ) are presented in Supplementary Table 1. Included men were slightly younger (34 versus 35 years; $P<0.001)$ and more often used alcohol (71.5 versus $66.9 \%$; $P<0.05)$. Overall, the study population were aged $34 \pm 4$ years (mean $\pm \mathrm{SD}$ ), with a BMI of $26.1 \pm 2.3 \mathrm{~kg} / \mathrm{m}^{2}$, and sympathomimetic use was reported by $3.6 \%$. TABLE 1 shows the general characteristics of the study population divided into men using sympathomimetics $(n=32)$ and those not using any medication $(n=850)$.
Sympathomimetic users showed a higher percentage of folic acid supplement use (24.1\% versus $6.0 \% ; P<0.001)$ and a higher percentage of progressive motile spermatozoa (48\% versus 38\%; $P<0.05$ ) than non-medication users (TABLE 1).

After adjustment for potential confounders, i.e. smoking, alcohol use, age, geographic background, BMI, folic acid supplement use and the four astronomical seasons, multivariable linear regression analyses revealed that the use of sympathomimetics compared with no medication use remained positively associated with a $10 \%$ higher percentage of progressive motile spermatozoa ( model 1 ; beta $=10.859 ; 95 \% \mathrm{Cl}$ 3.977-17.742). By additionally adjusting for asthmatic disease, the significantly positive association between the use of sympathomimetics and percentage progressive motile spermatozoa remained $($ model 2 ; beta $=10.265 ; 95 \%$ Cl 3.258-17.272) (TABLE 2).

In a subgroup analysis of men with TMSC $<$ or $\geq 10$ million, these positive associations remained, but only in men with TMSC $<10$ million (Supplementary Table 2). Moreover, after adjustment for potential confounders, sperm concentration was also positively associated with the use of sympathomimetics, but was only statistically significant in men with TMSC $\geq 10$ million (Supplementary Table 2). Stratifying the study population in men with TMSC $<$ or $\geq 3$ million and in men with TMSC $<$ or $\geq 1$ million did not significantly change the associations, although the use of

\section{TABLE 2 UNI- AND MULTIVARIABLE LINEAR REGRESSION MODELS OF MEN OF SUBFERTILE COUPLES ( $\mathbf{N}=882$ )}

\begin{tabular}{|c|c|c|c|c|c|}
\hline Sympathomimetics & $\begin{array}{l}\text { Ejaculate volume } \\
\sqrt{ }(\mathrm{ml}) \text { beta }(95 \% \mathrm{Cl})\end{array}$ & $\begin{array}{l}\text { Sperm concentration } \\
\sqrt[4]{ }\left(10^{6} / \mathrm{ml}\right) \text { beta }(95 \% \\
\mathrm{Cl})\end{array}$ & $\begin{array}{l}\text { Sperm count } \sqrt{ }\left(10^{6} /\right. \\
\text { ejaculate) beta }(95 \% \\
\mathrm{Cl})\end{array}$ & $\begin{array}{l}\text { TMSC } \sqrt[4]{ }\left(10^{6} / \text { ejaculate }\right) \\
\text { beta }(95 \% \mathrm{Cl})\end{array}$ & $\begin{array}{l}\text { Sperm motility } \\
(A+B \%) \text { beta }(95 \% \\
\text { CI) }\end{array}$ \\
\hline nadjusted ( $n=882$ ) & $-0.103(-0.268,0.063)$ & $0.166(-0.149,0.481)$ & $0.465(-1.732,2.662)$ & $0.161(-0.212,0.534)$ & $8.224(1.798,14.651)^{\star}$ \\
\hline Model $1(n=795)$ & $-0.119(-0.298,0.060)$ & $0.287(-0.049,0.623)$ & $1.123(-1.210,3.456)$ & $0.301(-0.097,0.699)$ & $10.859(3.977,17.742)^{*}$ \\
\hline Model $2(n=795)$ & $-0.111(-0.293,0.072)$ & $0.279(-0.062,0.621)$ & $1.093(-1.284,3.470)$ & $0.285(-0.121,0.690)$ & $10.265(3.258,17.272)^{*}$ \\
\hline
\end{tabular}

Note: data depicted as beta and confidence interval $(95 \% \mathrm{Cl})$.

${ }^{*} P<0.05$. The regression coefficient (beta) indicates the increase or decrease (-) change per unit of the sperm parameter. Model 1: adjusted for smoking, alcohol use, age, geographic background, BMI, folic acid supplement use and the four astronomical seasons. Model 2: model 1 with additional adjustment for asthma/bronchitis. BMI = body mass index; $\mathrm{Cl}=$ confidence interval. 
sympathomimetics was only significantly associated with sperm motility in men with TMSC $\geq 1$ and $\geq 3$ million (model 2; beta $=6.890 ; 95 \% \mathrm{Cl} 1.409-12.371$ and model 2 ; beta $=8.205 ; 95 \% \mathrm{Cl}$ 2.290-14.120 for TMSC $\geq 3$ million and $\geq 1$ million, respectively) (Supplementary Table 3). Moreover, in men with TMSC $\geq 3$ million, use of sympathomimetics was significantly associated with less ejaculate volume after adjustment for potential confounders (model 2; beta $=-0.196$; 95\% Cl -0.379-0.012) (Supplementary Table 3).

As corticosteroids were also used by some men in the study population, associations between corticosteroid use and semen quality were also studied, but showed no significant associations (data not shown).

\section{DISCUSSION}

This study demonstrates that the use of sympathomimetics is associated with a significantly higher percentage progressive motile spermatozoa (type $A+B$ ) independent of corticosteroid use. Moreover, in men with TMSC $\geq 10$ million, sperm concentration was also positively associated with the use of sympathomimetics. These positive associations remained after adjustment for potential confounders and confounding by indication.

Sympathomimetics are agonists for beta-adrenergic receptors, a class of $G$ protein-coupled receptors, resulting in stimulation of the sympathetic nervous system. This activation of beta-adrenergic receptors is followed by activation of the enzyme adenylate cyclase, which in turn leads to activation of the secondary messenger cyclic adenosine monophosphate (CAMP), which activates protein kinase A (PKA) (Rang and Dale, 2012). Testicular spermatozoa develop the capacity for motility during transit through the epididymis (Dacheux and Dacheux, 2014). Therefore, a possible explanation for the positive association between the use of sympathomimetics and percentage progressive motile spermatozoa may be related to the increase in CAMP and PKA, because these signalling pathways, together with the calcium pathway, are known to be the most central to the regulation of sperm motility (Turner, 2006). This hypothesis is substantiated by Esposito et al. (2004), showing a time-dependent recovery of sperm motility in mice with impaired motility, after loading with cAMP.

Several studies have indicated that normal function of the alpha-adrenergic receptor is necessary for normal contraction of the vas deferens and seminal vesicles and consequent sperm ejaculation (Sanbe et al., 2007; van Dijk et al., 2006). By stimulation of the beta-receptors, the vasoconstrictive effect of the alphareceptors decreases. This may explain the negative trend this study found between the use of sympathomimetics and ejaculate volume. The significantly positive association with sperm concentration found in the subgroup of men with TMSC $\geq 10$ million is suggested to be a direct consequence of the decrease in ejaculate volume, as sperm concentration is the product of sperm count multiplied by ejaculate volume.

The FDA states that sympathomimetics are safe to use on a daily basis for the indication of asthmatic disease, but surprisingly, data on the effects on semen parameters are missing (US Food and Drug Administration). In future, the use of sympathomimetics could be considered to enhance sperm motility in subfertile men, especially because of the relatively mild adverse effects and acceptable route of administration. This is of interest because of the few therapeutic alternatives to enhance male fertility with selective oestrogen receptor modulators, such as clomiphene citrate and tamoxifen, with more frequent adverse effects than sympathomimetics, such as nausea, headache, alteration in libido, visual field changes and gynecomastia (Ramasamy et al., 2014; Siddiq and Sigman, 2002; Wiehle et al., 2014).

This study is limited by the fact that only one semen analysis was taken into account, which does not account for intra-individual variation in semen parameters. Because the study only included men as cases when they used the specific medication at the time of the actual study visit, the number of cases is relatively small. Some heterogeneity caused by an unknown combination of diseases and the fact that not every disease is always treated could have negatively affected the estimates. Moreover, dose-response effects could not be studied to further estimate causality of the observed associations. Lastly, this study was performed in men of subfertile couples and therefore the external validity is limited. However, the majority of men had normospermia with most parameters above the lower reference limit, which in contrast, does makes the results generalizable to all men.

Major strengths of this study are the standardized data collection by a trained researcher of a large group of men of subfertile couples visiting one tertiary hospital and the fact that semen analyses were performed at one laboratory. Moreover, the time period between measurement of sperm parameters and study entry visit was strictly set, so it reflects the sensitive exposure window of male spermatogenesis of approximately 70 days. Besides, several confounders, including the use of other medicines, were included in the analyses, confounding by indication was excluded and stratified analyses were performed in order to contribute to personalized medicine in the future.

The current study demonstrates that the use of sympathomimetics is positively associated with sperm motility in men of subfertile couples. Moreover, in men with $\mathrm{TMSC} \geq 10$ million, use of sympathomimetics was also positively associated with sperm concentration. This explorative data suggests that male subfertility could be a new indication for a secondary use of sympathomimetics, a novel finding that needs to be interpreted with caution and emphasizes the need for further research on causality.

\section{ACKNOWLEDGEMENTS}

The authors thank the 'Achieving a Healthy Pregnancy' team of the outpatient clinic of the Department of Obstetrics and Gynecology at the Erasmus University Medical Center in Rotterdam, the Netherlands, for their contribution to the data collection.

This study was funded by the Department of Obstetrics and Gynecology of the Erasmus MC and an additional grant from ZonMW (the Netherlands Organisation for Health Research and Development; project number 902040003).

\section{SUPPLEMENTARY MATERIALS}

Supplementary material associated with this article can be found, in the online version, at doi:10.1016/j.rbmo.2019.12.009. 


\section{REFERENCES}

Boerdam, A., Knoops, K., 2016. Astma en copd in beeld. mei, Cbs Statline Netherlands, 2015. Health and wellbeing: Use of medication. file:///C:/Users/627000/Downloads/2016-astmaen-copd-in-beeld\%20(1).pdf

Cbs Statline Netherlands, 2015 Health and wellbeing: Use of medication. https:// opendata.cbs.nl/statline/\#/CBS/nl/ navigatieScherm/thema?thema $\mathrm{Nr}=3770$

Dacheux, J.L., Dacheux, F. New insights into epididymal function in relation to sperm maturation. Reproduction 2014; 147: R27-R42

Eisenberg, M.L., Li, S., Behr, B., Pera, R.R., Cullen, M.R. Relationship between semen production and medical comorbidity. Fertil. Steril. 2015; 103: 66-71

European Society of Human Reproduction and Embryology, 2016. ART fact sheet. https://www. eshre.eu/Press-Room/Resources

Esposito, G., Jaiswal, B.S., Xie, F., KrajncFranken, M.A., Robben, T.J., Strik, A.M., Kuil, C., Philipsen, R.L., Van Duin, M., Conti, M., Gossen, J.A. Mice deficient for soluble adenylyl cyclase are infertile because of a severe sperm-motility defect. Proc. Natl. Acad. Sci. U S A 2004; 101: 2993-2998

Fody, E.P., Walker, E.M. Effects of drugs on the male and female reproductive systems. Ann. Clin. Lab. Sci. 1985; 15: 451-458

Global Initiative for Asthma, 2017. Global strategy for asthma management and prevention, 2017. https://ginasthma.org/wp-content/ uploads/2017/02/wms-Main-pocket-guide_2017. pdf

Hammiche, F., Laven, J.S., Van Mil, N., De Cock, M., De Vries, J.H., Lindemans, J., Steegers, E.A., Steegers-Theunissen, R.P. Tailored preconceptional dietary and lifestyle counselling in a tertiary outpatient clinic in the Netherlands. Hum. Reprod. 2011; 26 2432-2441

Hayashi, T., Miyata, A., Yamada, T. The impact of commonly prescribed drugs on male fertility. Hum. Fertil. (Camb) 2008; 11: 191-196
Hayashi, T., Yoshinaga, A., Ohno, R., Ishii, N., Kamata, S., Watanabe, T., Yamada, T. Asthenozoospermia: Possible association with long-term exposure to an anti-epileptic drug of carbamazepine. Int. J. Urol. 2005; 12: $113-114$

Huijgen, N.A., De Ridder, M.A., Verhamme, K.M., Dohle, G.R., Vanrolleghem, A.M., Sturkenboom, M.C., Laven, J.S., SteegersTheunissen, R.P. Are proton-pump inhibitors harmful for the semen quality of men in couples who are planning pregnancy? Fertil. Steril. 2016; 106: 1666-1672

Huijgen, N.A., Goijen, H.J., Twigt, J.M., Mulders, A.G., Lindemans, J., Dohle, G.R., Laven, J.S., Steegers-Theunissen, R.P. Effect of medications for gastric acid-related symptoms on tota motile sperm count and concentration: A case-control study in men of subfertile couples from the Netherlands. Drug Saf. 2017; 40: $241-248$

Ramasamy, R., Scovell, J.M., Kovac, J.R., Lipshultz, L.I. Testosterone supplementation versus clomiphene citrate for hypogonadism: An age matched comparison of satisfaction and efficacy. J. Urol. 2014; 192: 875-879

Rang, H.P.a.D., M.M., 2012. Rang and dale's pharmacology, seventh edition, Seventh ed.

Samplaski, M.K., Nangia, A.K., 2015. Adverse effects of common medications on male fertility. 12, 401-413

Sanbe, A., Tanaka, Y., Fujiwara, Y., Tsumura, H., Yamauchi, J., Cotecchia, S., Koike, K., Tsujimoto, G., Tanoue, A. Alpha1adrenoceptors are required for normal male sexual function. Br. J. Pharmacol. 2007; 152: 332-340

Schlegel, P.N., Chang, T.S., Marshall, F.F. Antibiotics: Potential hazards to male fertility. Fertil. Steril. 1991; 55: 235-242

Semet, M., Paci, M., Saias-Magnan, J., MetzlerGuillemain, C., Boissier, R., Lejeune, H., Perrin, $J$. The impact of drugs on male fertility: A review. Andrology 2017; 5: 640-663

Siddiq, F.M., Sigman, M. A new look at the medical management of infertility. Urol. Clin. North Am. 2002; 29: 949-963
Sjoblom, T., West, A., Lahdetie, J. Apoptotic response of spermatogenic cells to the germ cell mutagens etoposide, adriamycin, and diepoxybutane. Environ. Mol. Mutagen 1998; 31: 133-148

The Dutch College of General Practitioners, 2007. Asthma in adults. https://www.nhg. org/standaarden/samenvatting/astma-bijvolwassenen

Turner, R.M. Moving to the beat: A review of mammalian sperm motility regulation. Reprod. Fertil. Dev. 2006; 18: 25-38

Us Food and Drug Administration, Long-acting beta agonist (laba) information.

Van Dijk, M.M., De La Rosette, J.J., Michel, M.C Effects of alpha(1)-adrenoceptor antagonists on male sexual function. Drugs 2006; 66 287-301

WHO Collaborating Centre for Drug Statistics Methodology, Structure and principles. https:// www.whocc.no/atc/structure and principles/

WHO Collaborating Centre for Drug Statistics Methodology. 2017 Guidelines for ATC classification and DDD assignment. Norwegian Institute of Public Health https://www.whocc.no/ atc_ddd_index_and_guidelines/guidelines/

Wiehle, R.D., Fontenot, G.K., Wike, J., Hsu, K., Nydell, J., Lipshultz, L., Group, Z.a.C.S Enclomiphene citrate stimulates testosterone production while preventing oligospermia: A randomized phase ii clinical trial comparing topical testosterone. Fertil. Steril. 2014; 102: 720-727

World Health Organization. [laboratory manual of the who for the examination of human semen and sperm-cervical mucus interaction]. Ann. Ist Super Sanita 2010; 37: 1-123

$\mathrm{WHO}$ laboratory manual for the examination and processing of human semen. Fifth Edition, 2010, ISBN 9789241547789

Received 6 June 2019; received in revised form 31 October 2019; accepted 16 December 2019. 